\title{
A composite structure based on reduced graphene oxide and metal oxide nanomaterials for chemical sensors
}

\author{
Vardan Galstyan ${ }^{* 1,2}$, Elisabetta Comini ${ }^{1,2}$, Iskandar Kholmanov ${ }^{1,3}$, Andrea Ponzoni ${ }^{1,2}$, \\ Veronica Sberveglieri ${ }^{1}$, Nicola Poli ${ }^{2}$, Guido Faglia ${ }^{1,2}$ and Giorgio Sberveglieri ${ }^{1,2}$
}

\author{
Full Research Paper \\ Address: \\ ${ }^{1}$ Sensor Lab, CNR, National Institute of Optics (INO), Via Valotti 9 , \\ 25133 Brescia, Italy, ${ }^{2}$ Sensor Lab, Department of Information \\ Engineering, University of Brescia, Via Valotti 9, 25133 Brescia, Italy \\ and ${ }^{3}$ Department of Mechanical Engineering, The University of Texas \\ at Austin, Austin, TX 78712, USA \\ Email: \\ Vardan Galstyan* - vardan.galstyan@unibs.it \\ * Corresponding author \\ Keywords: \\ chemical sensors; reduced graphene oxide (RGO); volatile organic \\ compounds; zinc oxide ( $\mathrm{ZnO})$
}

Beilstein J. Nanotechnol. 2016, 7, 1421-1427.

doi:10.3762/bjnano.7.133

Received: 03 July 2016

Accepted: 19 September 2016

Published: 10 October 2016

This article is part of the Thematic Series "Functional materials for environmental sensors and energy systems".

Guest Editor: M. Penza

(C) 2016 Galstyan et al.; licensee Beilstein-Institut. License and terms: see end of document.

\begin{abstract}
A hybrid nanostructure based on reduced graphene oxide and $\mathrm{ZnO}$ has been obtained for the detection of volatile organic compounds. The sensing properties of the hybrid structure have been studied for different concentrations of ethanol and acetone. The response of the hybrid material is significantly higher compared to pristine $\mathrm{ZnO}$ nanostructures. The obtained results have shown that the nanohybrid is a promising structure for the monitoring of environmental pollutants and for the application of breath tests in assessment of exposure to volatile organic compounds.
\end{abstract}

\section{Introduction}

Hazard analysis of critical control point (HACCP) systems address food safety through the identification and control of the major food risks, i.e., biological, chemical and physical hazards. The metabolic activity of microorganisms in dairy foods leads to breakdown of chemical compounds into alcohol and organic acids [1]. Consequently, early detection of ethanol on the surface of food products is necessary in order to avoid the subsequent hazards and to take steps to decrease the spoilage rate in food products. Besides, ethanol and acetone can be assigned to specific pathologies and may be utilized as breath markers [2] In particular, acetone is a selective breath marker and the pres- ence of its certain concentrations in breath can reflect metabolic products of diabetes [3]. Due to the development of chemical industries acetone is one of the most commonly used volatile organic compounds (VOCs) and can cause dangerous health issues such as blindness, allergies and unconsciousness [4]. Therefore, the detection of VOCs such as acetone and ethanol is essential.

Nowadays, chemical and physical methods for environmental and medical diagnostics are rapidly developing. Medical monitoring technologies mainly focus on breath and blood for clini- 
cal diagnostics $[5,6]$. During the last decades, different types of sensors were fabricated for environmental and health monitoring. Among the different detection systems, chemical sensors based on metal oxide nanomaterials are highly demanded because of their high sensitivity, small size, low cost and low power consumption [7,8]. Metal oxide sensors can detect ethanol and acetone only at high operating temperatures $\left(\geq 300{ }^{\circ} \mathrm{C}\right)[7,9,10] . \mathrm{ZnO}$ is a extensively studied and inspiring material due to its unique properties, namely the wide bandgap and large exciton binding energy [11]. Most of the literature is focused on the synthesis of $\mathrm{ZnO}$ films, nanowires and $\mathrm{ZnO}$ based hybrids for applications in opto-electronics as well as in gas sensors [7,12-15]. $\mathrm{ZnO}$ has several advantages regarding the application in sensor structures. However, there are many obstacles (high resistivity and operating temperature, sensitivity and selectivity) with respect to the application of $\mathrm{ZnO}$ nanomaterials in chemical gas sensors that need to be overcome $[7,14]$.

Hybrid structures composed of two or more different materials with diverse functional properties are of great interest to develop advanced composite materials for numerous applications $[16,17]$. Graphene-based materials are very attractive because of their specific properties and large surface area $[18,19]$. Several new kinds of graphene-based structures were developed in rapid succession, which raises great interest nowadays and the exclusive properties of these materials make them a suitable candidate for various applications [20,21]. Recently we have shown that the functionalization of $\mathrm{ZnO}$ with reduced graphene oxide ( $\mathrm{RGO}$ ) sheets improved its sensing performance for $\mathrm{NO}_{2}$ and $\mathrm{H}_{2}$ [22]. Abideen et al. also improved the response of $\mathrm{ZnO}$ towards $\mathrm{H}_{2}$ preparing $\mathrm{ZnO}$ nanofibers loaded with reduced graphene oxide [23]. These recent studies indicate that the combination of graphene and its modified structures with $\mathrm{ZnO}$ nanomaterials may open new perspectives for the fabrication of $\mathrm{ZnO}$-based chemical sensors.

In this paper, we describe a hybrid nanomaterial consisting of $\mathrm{RGO}$ and $\mathrm{ZnO}$ with a highly improved performance in sensing the VOCs ethanol and acetone. The highly improved sensing behavior of the obtained structures shows that our hybrid nanomaterial may be used to fabricate gas sensor devices for the detection of VOCs.

\section{Experimental}

The method used for fabricating the $\mathrm{ZnO}$ nanostructures is similar to that described in our previous work [24]. Thin films of metallic $\mathrm{Zn}$ with a thickness of $600 \mathrm{~nm}$ were deposited on $2 \mathrm{~mm}$ square alumina substrates by means of radio frequency (RF) magnetron sputtering. Thin deposited films of $\mathrm{Zn}$ were anodized in $2 \mathrm{M}$ oxalic acid dihydrate $\left(\mathrm{C}_{2} \mathrm{H}_{2} \mathrm{O}_{4} \cdot 2 \mathrm{H}_{2} \mathrm{O}\right)$ containing ethanol using a two-electrode system. A platinum foil was used as a counter electrode and the anodization process was carried out at room temperature. The obtained structures were zinc oxalate dihydrate $\left(\mathrm{ZnC}_{2} \mathrm{O}_{4} \cdot 2 \mathrm{H}_{2} \mathrm{O}\right)$. The as-prepared samples were transformed to crystalline $\mathrm{ZnO}$ by thermal annealing in a furnace at $400{ }^{\circ} \mathrm{C}$ as we have described in [25].

We prepared the composite material using the method described in [22]. We produced graphite oxide from natural graphite (SP-1, Bay Carbon) by means of modified Hummers method [26]. Then, we prepared aqueous dispersions of GO by stirring graphite oxide solids in pure water $(18.0 \mathrm{M} \Omega \cdot \mathrm{cm}$ resistivity, purchased from Barnstead) for $3 \mathrm{~h}$ and sonicated the resulting mixture (VWR B2500A-MT bath sonicator) for $45 \mathrm{~min}$. This method yields well-dispersed GO in water. We drop-cast the obtained aqueous dispersion of $\mathrm{GO}$ onto $\mathrm{ZnO}$ nanostructures and annealed the prepared hybrid material in a furnace at $250{ }^{\circ} \mathrm{C}$ in an atmosphere of $20 \% \mathrm{O}_{2}$ and $80 \%$ Ar for $1 \mathrm{~h}$.

The surface morphology of the samples was studied by means of a LEO 1525 scanning electron microscope (SEM) equipped with a field emission gun. Energy dispersive X-ray spectroscopy (EDX) was used to quantify the elemental composition of the obtained materials. GO platelets were deposited onto Si substrates and characterized by Raman spectroscopy (WITec Micro-Raman Spectrometer Alpha 300, $\lambda=532 \mathrm{~nm}$, $100 \times$ objective).

To perform gas sensing measurements, the platinum electrodes and the heater were deposited on the front and rear sides of the alumina substrate, respectively. During gas sensing tests, the conductance of the samples was monitored by means of the volt-amperometric technique and the applied voltage during the measurements was $1 \mathrm{~V}$. We recorded the resistance of the structures every $30 \mathrm{~s}$. Measurements were carried out by means of a flow-through technique at atmospheric pressure, using a constant synthetic airflow $(0.3 \mathrm{~L} / \mathrm{min})$ as carrier gas for the analyte dispersion. During the experiments the relative humidity was $50 \%$. Gas response $(\mathrm{R})$ was defined as $\left[R=\left(G_{\mathrm{f}}-G_{0}\right) / G_{0}\right]$, where $G_{0}$ is the sample conductance in air, and $G_{\mathrm{f}}$ is the sample conductance in presence of the analyte gas.

\section{Results and Discussion Morphological and structural characteristics}

For characterizing the GO samples with SEM, an aqueous dispersion was spin-coated onto a silicon wafer at $4000 \mathrm{rpm}$ for 2 min. A typical SEM image of the GO platelets is shown in Figure 1a. The lateral size of GO platelets exhibits a wide distribution ranging from several nanometers up to about 20 micrometers. Figure $1 \mathrm{~b}$ shows the typical Raman spectrum of GO platelets with high intensity $D\left(\approx 1350 \mathrm{~cm}^{-1}\right)$ and $\mathrm{G}$ $\left(\approx 1580 \mathrm{~cm}^{-1}\right)$ peaks. The Raman D band of graphene is acti- 

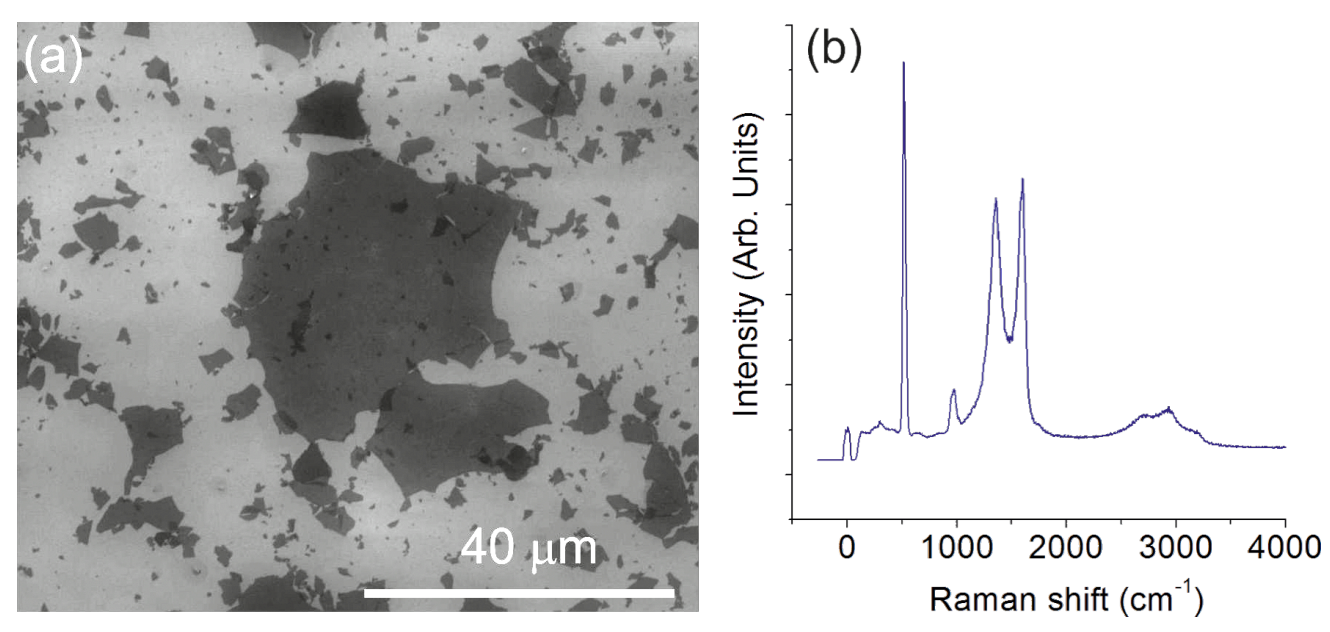

Figure 1: SEM image (a) and Raman spectrum (b) of the GO platelets deposited on $\mathrm{SiO}_{2} / \mathrm{Si}$ wafer.

vated by the defects that cause an inter-valley double resonance involving transitions near two inequivalent $\mathrm{K}$ points at neighboring corners of the first Brillouin zone of graphene [27]. Due to the decrease in size of the in-plane $\mathrm{sp}^{2}$-hybridzed domains after extensive oxidation and ultrasonic exfoliation, the GO exhibits a broad and intense D band in its Raman spectrum [28]. The intensity ratio between $\mathrm{D}$ and $\mathrm{G}$ peaks $\left(I_{\mathrm{D}} / I_{\mathrm{G}}=0.94\right)$ also indicates the high defect concentration in GO platelets. High intensity peaks at about $520 \mathrm{~cm}^{-1}$ and $950 \mathrm{~cm}^{-1}$ in the Raman spectrum can be attributed to the silicon substrate.

The morphology of the obtained hybrid material at different magnifications is shown in Figure 2. The $\mathrm{ZnO}$ nanoparticles have an average diameter of ca. $20 \mathrm{~nm}$ and form a porous structure of chain-like agglomerates [24]. As can be seen in the images $\mathrm{GO}$ platelets decorate the $\mathrm{ZnO}$ nanoparticles.

Figure 3 reports the EDX spectrum and the quantitative analysis of the prepared structure. The morphological and the compo- sitional studies confirm that the surface of $\mathrm{ZnO}$ nanomaterial is partially covered by GO. The variation of the $\mathrm{C} / \mathrm{O}$ ratio in the GO platelets was checked by EDX before and after the thermal treatment at $250{ }^{\circ} \mathrm{C}$. The EDX observations indicate that the $\mathrm{C} / \mathrm{O}$ ratio increased due to the treatment, which means that GO was partially reduced (Table 1 ). The obtained results are in agreement with the our previous work on a similar material for the detection of explosive and toxic gases [22].

\section{VOC sensing performance}

The sensing measurements were performed with ethanol and acetone at working temperatures ranging from 20 to $250^{\circ} \mathrm{C}$. Before each measurement, we stabilized the obtained structures for $8 \mathrm{~h}$ at the operating temperature in ambient air. The sensing tests revealed that both pure $\mathrm{ZnO}$ and the hybrid materials exhibit enhanced response kinetics and response amplitudes when the operating temperature is increased. As a result, the best sensing results were obtained at the maximum sensor temperature $\left(250^{\circ} \mathrm{C}\right)$.
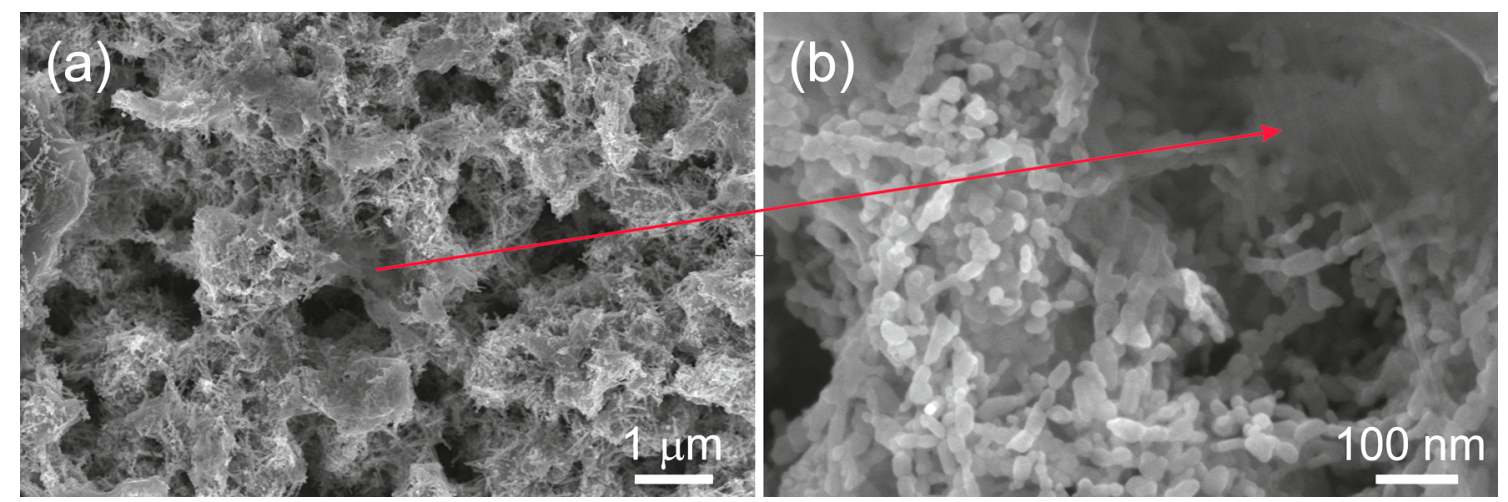

Figure 2: SEM images of the obtained samples based on graphene and zinc oxide at low (a) and high (b) magnification. 


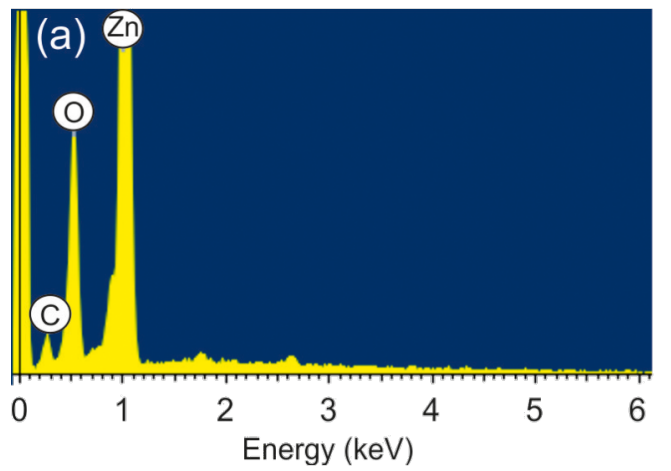

\begin{tabular}{|c|c|}
\hline (b) Element & Atom \% \\
\hline Zn & $42 \pm 7 \%$ \\
\hline$O$ & $43 \pm 7 \%$ \\
\hline C & $15 \pm 10 \%$ \\
\hline
\end{tabular}

Figure 3: (a) EDX spectrum and (b) quantitative analysis of the hybrid structure based on $\mathrm{GO}$ and $\mathrm{ZnO}$ annealed at $250{ }^{\circ} \mathrm{C}$.

Table 1: The results of the compositional analysis of as-prepared and annealed samples (at 100 and $250{ }^{\circ} \mathrm{C}$ ) on $\mathrm{SiO}_{2} / \mathrm{Si}$ wafers.

annealing
temperature $\left({ }^{\circ} \mathrm{C}\right)$

$\begin{array}{lll}\text { as-prepared sample } & 62 & 38 \\ 100 & 69 & 31 \\ 250 & 77 & 23\end{array}$

Figure 4 shows the response and the recovery curves of the prepared $\mathrm{ZnO}$ and $\mathrm{RGO}-\mathrm{ZnO}$ structures towards acetone and ethanol at an operating temperature of $250^{\circ} \mathrm{C}$. Since $\mathrm{ZnO}$ is an n-type semiconductor, when it is exposed to air at elevated temperatures the oxygen molecules are adsorbed on the surface of the material generating the electron depletion layer. The adsorbed oxygen mainly forms $\mathrm{O}^{-}$ions on the material surface (Equation 1) at temperatures of $200{ }^{\circ} \mathrm{C}$ or above [29]. As the reducing gas such as acetone (or ethanol) was introduced to the test chamber, the gas reacts with the adsorbed $\mathrm{O}^{-}$ions. This results in less ionic oxygen species on the surface and, consequently, in an increased conductance of the structures. The proposed reactions with acetone and ethanol that lead to a sensing signal are resumed in Equations 2-4 [30,31] and Equation 5 [32], respectively. A schematic representation of the sensing mechanism between the acetone and the RGO- $\mathrm{ZnO}$ structure is shown in Figure 5. As can be seen in Figure 4, an obvious increase of conductance was observed by exposing the sensor to acetone and ethanol indicating that the nanohybrid structure is able the detect VOCs. The conductance of the sensor after the gas test was recovered to the initial value proving a reversible interaction between the analyte gases and the structure.

$$
\mathrm{O}_{2}+2 \mathrm{e}^{-} \rightarrow 2 \mathrm{O}^{-}
$$

$$
\begin{gathered}
\mathrm{CH}_{3} \mathrm{COCH}_{3}+\mathrm{O}^{-} \rightarrow \mathrm{CH}_{3} \mathrm{COC}^{+} \mathrm{H}_{2}+\mathrm{OH}^{-}+\mathrm{e}^{-} \\
\mathrm{CH}_{3} \mathrm{COCH}_{3}+\mathrm{O}^{-} \rightarrow \mathrm{CH}_{3} \mathrm{C}^{+} \mathrm{O}+\mathrm{CH}_{3} \mathrm{O}^{-}+\mathrm{e}^{-} \\
\mathrm{CH}_{3} \mathrm{COCH}_{3}+8 \mathrm{O}^{-} \rightarrow 3 \mathrm{CO}_{2}+3 \mathrm{H}_{2} \mathrm{O}+8 \mathrm{e}^{-} \\
\mathrm{C}_{2} \mathrm{H}_{5} \mathrm{OH}+6 \mathrm{O}^{-} \rightarrow 2 \mathrm{CO}_{2}+3 \mathrm{H}_{2} \mathrm{O}+6 \mathrm{e}^{-}
\end{gathered}
$$
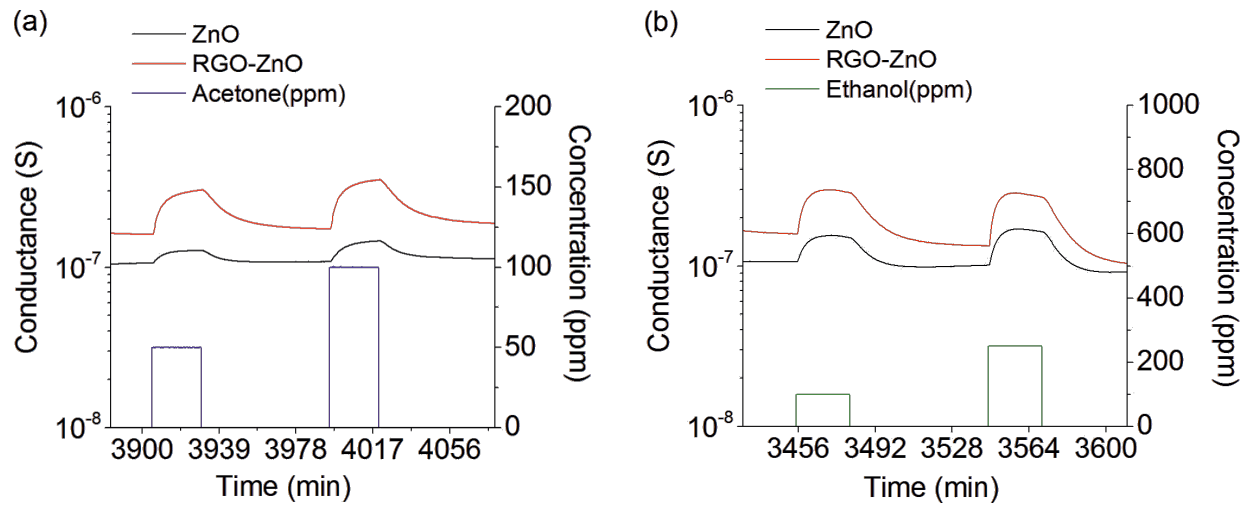

Figure 4: Dynamical response of $\mathrm{ZnO}$ and $\mathrm{RGO}-\mathrm{ZnO}$ structures at $250{ }^{\circ} \mathrm{C}$ and $\mathrm{RH}=50 \% @ 20^{\circ} \mathrm{C}$ : (a) towards 50 and 100 ppm of acetone and (b) towards 100 and $250 \mathrm{ppm}$ of ethanol. 


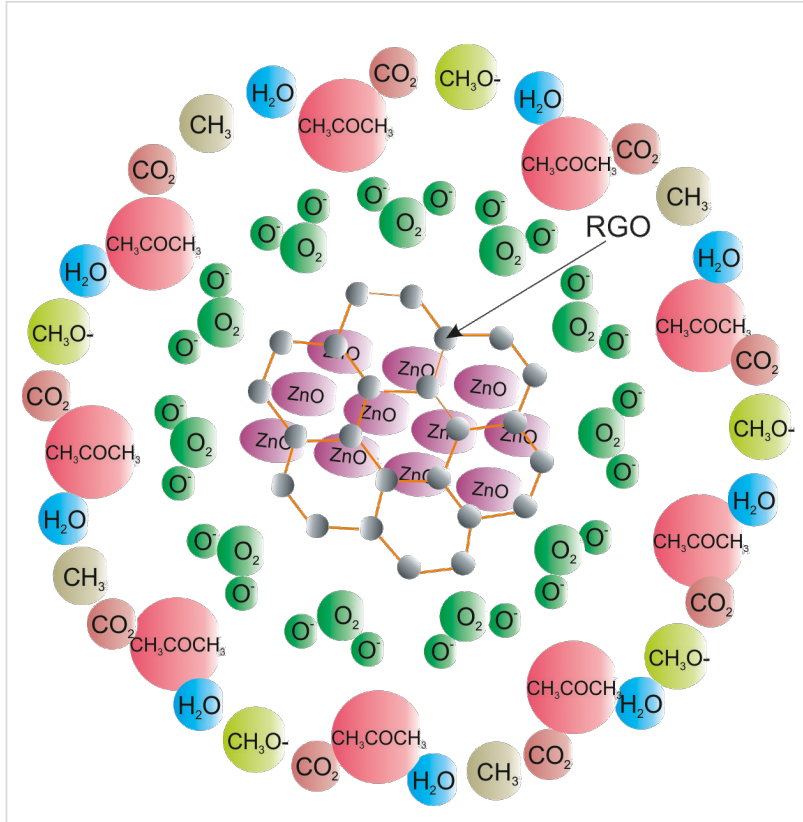

Figure 5: Schematic diagram of the sensing mechanism between acetone and the RGO-ZnO structure: Oxygen is absorbed on the structure creating $\mathrm{O}^{-}$species (Equation 1). Upon exposure to acetone, acetone molecules adsorb and donate the electrons to the adsorbed oxygen species (Equations 2-4) forming $\mathrm{CO}_{2}, \mathrm{H}_{2} \mathrm{O}$ and other compounds such as $\mathrm{CH}_{3}, \mathrm{CH}_{3} \mathrm{O}^{-}$.

We compared the sensing performance of the RGO-ZnO hybrid structure with a pristine $\mathrm{ZnO}$ nanostructure (Figure 6). The response of the nanohybrid towards both gases is much higher compared to the pristine $\mathrm{ZnO}$. The response values of RGO- $\mathrm{ZnO}$ and $\mathrm{ZnO}$ towards $100 \mathrm{ppm}$ of acetone are 140 and $35 \%$, respectively. The response values towards $100 \mathrm{ppm}$ of ethanol are $120 \%$ for RGO-ZnO and $55 \%$ for $\mathrm{ZnO}$. These results demonstrate that the presence of RGO results in a four times higher response to $100 \mathrm{ppm}$ of acetone compared to pure $\mathrm{ZnO}$. The $\mathrm{RGO}-\mathrm{ZnO}$ response to the same concentration of ethanol is about 2.2 times higher compared to $\mathrm{ZnO}$. The improvement of the sensing properties in the presence of RGO may be reasonably ascribed to the enhancement of the overall surface of the hybrid material, which would benefit the reactivity of both phases ( $\mathrm{ZnO}$ and $\mathrm{RGO})$ [33].

The hybrid material shows a higher response to acetone than to ethanol. From the formulas describing the sensing mechanism of acetone (Equations 2-4) and ethanol (Equation 5) and the sensing result of the $\mathrm{RGO}-\mathrm{ZnO}$ towards the same concentrations of target gas seems that at $250{ }^{\circ} \mathrm{C}$ acetone releases more electrons than ethanol due to the interaction between the gas molecules and the adsorbed oxygen on the material surface. It may be one of the reasons of the better response to acetone. Besides, different gases have a different adsorption rate due the variation of adsorption energy.

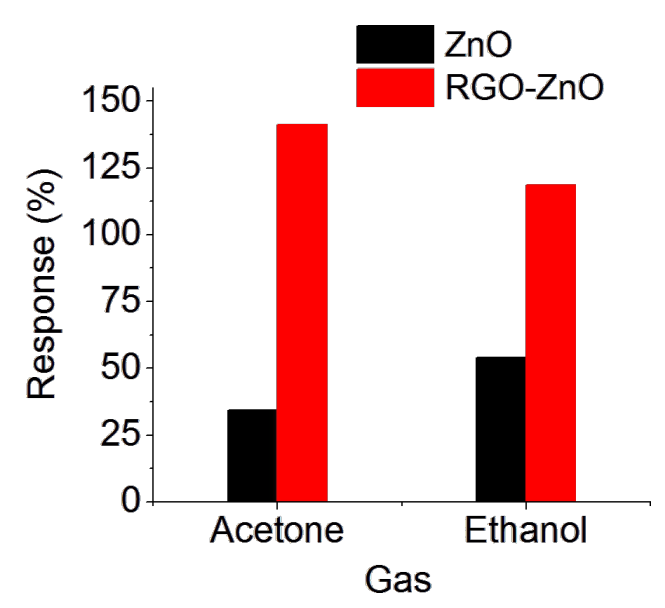

Figure 6: Response of $\mathrm{RGO}-\mathrm{ZnO}$ and pristine $\mathrm{ZnO}$ nanostructures towards $100 \mathrm{ppm}$ acetone and ethanol at a working temperature of $250{ }^{\circ} \mathrm{C}$ and in humid air (relative humidity $\mathrm{RH}=50 \% @ 20^{\circ} \mathrm{C}$ ).

Figure 7 reports the calibration curves of the RGO- $\mathrm{ZnO}$ and pristine $\mathrm{ZnO}$ nanostructures for measuring acetone at a working temperature of $250{ }^{\circ} \mathrm{C}$. The response for both structures shows good linearity with the concentration of acetone. The response of the hybrid structure towards all examined concentrations of acetone is greater compared to the pristine $\mathrm{ZnO}$ nanostructures. In addition to providing extra surface area for the adsorption sites and for the reaction with the analytes, the RGO platelets also may play a critical role in the electrical transport. RGO platelets reduce the height of the potential barrier for electron tunneling acting as a highly conductive electrical path for the transport of electrons through the nanostructure [34]. Therefore, RGO improves the sensing performance of $\mathrm{ZnO}$. Due to this reason, in our future investigations we will study the sensing properties of the composite material varying the concentration and the reducing regimes of RGO in the structure to find the best regimes for the practical applications.

\section{Conclusion}

In conclusion, chemiresistive gas sensors based on $\mathrm{ZnO}$ and RGO nanostructures with high sensing performance for the detection of VOCs have been developed. The sensing properties of the obtained structures have been investigated towards acetone and ethanol. To evaluate the sensing performance of the hybrid nanostructure we compared its properties with pristine $\mathrm{ZnO}$ nanostructures obtained with the same fabrication regimes. The sensing properties of $\mathrm{ZnO}$ have been improved because of the high surface area of RGO and nanostructured $\mathrm{ZnO}$, as well as due to the ability of RGO to enhance the transport of charge carriers in the structure. Finally, incorporation of RGO into the metal oxide nanomaterials is a promising strategy in the detection of VOCs for environmental and health protection. 


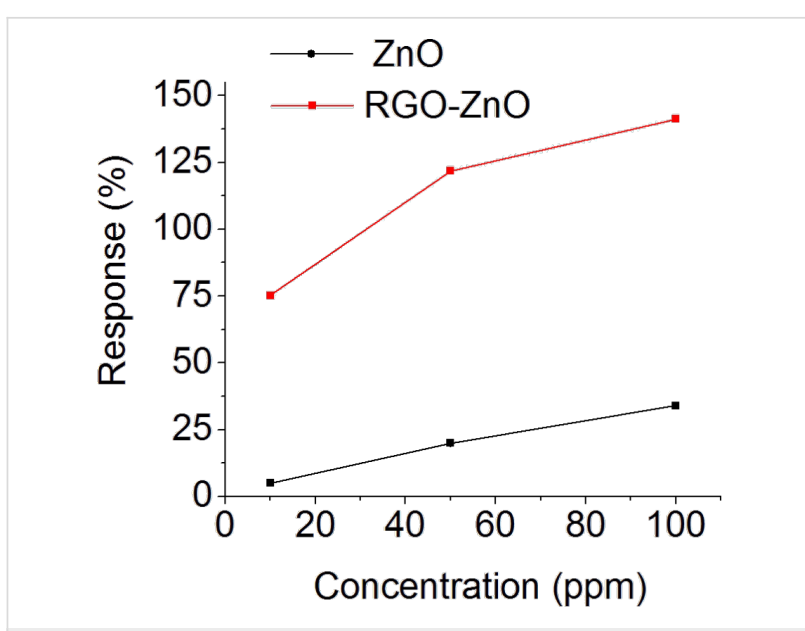

Figure 7: Calibration curve for acetone at an operating temperature of $250{ }^{\circ} \mathrm{C}$ and in a humid air background $\left(\mathrm{RH}=50 \% @ 20^{\circ} \mathrm{C}\right)$.

\section{Acknowledgements}

The research leading to these results has received funding from the following projects: "New approaches and methodologies for bioremediation of water contaminated by chlorinated aliphatic solvents (SUSBIOREM)" (funded by the National Research Council (CNR) and Lombardia Region); "MSP: Multi Sensor Platform for Smart Building Management" (grant agreement No. 611887, funded by the European Commission through its $7^{\text {th }}$ Framework Programme); "FIRB - Oxides at the nanoscale: multifunctionality and applications" (Protocollo: RBAP115AYN, funded by the Italian Ministry of Education).

\section{References}

1. Ledenbach, L. H.; Marshall, R. T. Microbiological Spoilage of Dairy Products. In Compendium of the Microbiological Spoilage of Foods and Beverages; Sperber, W. H.; Doyle, M. P., Eds.; Springer: Berlin, Germany, 2009; pp 41-67. doi:10.1007/978-1-4419-0826-1_2

2. Manolis, A. Clin. Chem. 1983, 29, 5-15.

3. Righettoni, M.; Tricoli, A. J. Breath Res. 2011, 5, 037109. doi:10.1088/1752-7155/5/3/037109

4. Gossel, T. A.; Bricker, J. D. Principles of clinical toxicology, 3rd ed.; Raven Press: New York, NY, U.S.A., 1994; p 447.

5. Righettoni, M.; Amann, A.; Pratsinis, S. E. Mater. Today 2015, 18, 163-171. doi:10.1016/j.mattod.2014.08.017

6. Di Natale, C.; Paolesse, R.; Martinelli, E.; Capuano, R. Anal. Chim. Acta 2014, 824, 1-17. doi:10.1016/j.aca.2014.03.014

7. Galstyan, V.; Comini, E.; Ponzoni, A.; Sberveglieri, V.; Sberveglieri, G. Chemosensors 2016, 4, 6. doi:10.3390/chemosensors4020006

8. Comini, E.; Faglia, G.; Sberveglieri, G., Eds. Solid State Gas Sensing; Springer: Berlin, Germany, 2009; v-vi. doi:10.1007/978-0-387-09665-0

9. Galstyan, V.; Comini, E.; Faglia, G.; Sberveglieri, G. Sensors 2013, 13, 14813-14838. doi:10.3390/s131114813

10. Devan, R. S.; Patil, R. A.; Lin, J.-H.; Ma, Y.-R. Adv. Funct. Mater. 2012, 22, 3326-3370. doi:10.1002/adfm.201201008

11. Morin, F. J. Semiconductors; Renhold Publishing Company: New York, NY, U.S.A., 1959.
12. Kołodziejczak-Radzimska, A.; Jesionowski, T. Materials 2014, 7, 2833-2881. doi:10.3390/ma7042833

13. Wang, Z. L. J. Phys.: Condens. Matter 2004, 16, R829-R858. doi:10.1088/0953-8984/16/25/R01

14. Spencer, M. J. S. Prog. Mater. Sci. 2012, 57, 437-486. doi:10.1016/j.pmatsci.2011.06.001

15. Kiriakidis, G.; Moschovis, K.; Kortidis, I.; Binas, V. Vacuum 2012, 86, 495-506. doi:10.1016/j.vacuum.2011.10.013

16. Muhammad, R.; Rekha, P.; Mohanty, P. RSC Adv. 2016, 6 , 17100-17105. doi:10.1039/C5RA25933A

17. Ionescu, R.; Espinosa, E. H.; Leghrib, R.; Felten, A.; Pireaux, J. J.; Erni, R.; Van Tendeloo, G.; Bittencourt, C.; Cañellas, N.; Llobet, E. Sens. Actuators, B 2008, 131, 174-182. doi:10.1016/j.snb.2007.11.001

18. Kholmanov, I. N.; Domingues, S. H.; Chou, H.; Wang, X.; Tan, C.; Kim, J.-Y.; Li, H.; Piner, R.; Zarbin, A. J. G.; Ruoff, R. S. ACS Nano 2013, 7, 1811-1816. doi:10.1021/nn3060175

19. Schedin, F.; Geim, A. K.; Morozov, S. V.; Hill, E. W.; Blake, P.; Katsnelson, M. I.; Novoselov, K. S. Nat. Mater. 2007, 6, 652-655. doi:10.1038/nmat1967

20. Maarouf, A. A.; Kasry, A.; Chandra, B.; Martyna, G. J. Carbon 2016, 102, 74-80. doi:10.1016/j.carbon.2016.02.024

21. Dubal, D. P.; Holze, R.; Gomez-Romero, P. Sci. Rep. 2014, 4, 7349. doi:10.1038/srep07349

22. Galstyan, V.; Comini, E.; Kholmanov, I.; Faglia, G.; Sberveglieri, G. RSC Adv. 2016, 6, 34225-34232. doi:10.1039/C6RA01913G

23. Abideen, Z. U.; Kim, H. W.; Kim, S. S. Chem. Commun. 2015, 51, 15418-15421. doi:10.1039/C5CC05370F

24. Galstyan, V.; Comini, E.; Baratto, C.; Ponzoni, A.; Bontempi, E.; Brisotto, M.; Faglia, G.; Sberveglieri, G. CrystEngComm 2013, 15 , 2881-2887. doi:10.1039/c3ce27011d

25. Galstyan, V.; Comini, E.; Baratto, C.; Faglia, G.; Sberveglieri, G. Ceram. Int. 2015, 41, 14239-14244. doi:10.1016/j.ceramint.2015.07.052

26. Stankovich, S.; Dikin, D. A.; Dommett, G. H. B.; Kohlhaas, K. M.; Zimney, E. J.; Stach, E. A.; Piner, R. D.; Nguyen, S. T.; Ruoff, R. S. Nature 2006, 442, 282-286. doi:10.1038/nature04969

27. Ferrari, A. C. Solid State Commun. 2007, 143, 47-57. doi:10.1016/j.ssc.2007.03.052

28. Cancado, L. G.; Pimenta, M. A.; Saito, R.; Jorio, A.; Ladeira, L. O.; Grueneis, A.; Souza, A. G.; Dresselhaus, G.; Dresselhaus, M. S. Phys. Rev. B 2002, 66, 035415. doi:10.1103/PhysRevB.66.035415

29. Yamazoe, N.; Shimanoe, K. Sens. Actuators, B 2008, 128, 566-573. doi:10.1016/j.snb.2007.07.036

30. Xu, X. L.; Chen, Y.; Ma, S. Y.; Li, W. Q.; Mao, Y. Z. Sens. Actuators, B 2015, 213, 222-233. doi:10.1016/j.snb.2015.02.073

31. Wang, P.; Wang, D.; Zhang, M.; Zhu, Y.; Xu, Y.; Ma, X.; Wang, X. Sens. Actuators, B 2016, 230, 477-484. doi:10.1016/j.snb.2016.02.056

32. Bagheri, M.; Khodadadi, A. A.; Mahjoub, A. R.; Mortazavi, Y. Sens. Actuators, B 2016, 223, 576-585. doi:10.1016/j.snb.2015.09.137

33. Russo, P. A.; Donato, N.; Leonardi, S. G.; Baek, S.; Conte, D. E.; Neri, G.; Pinna, N. Angew. Chem., Int. Ed. 2012, 51, 11053-11057. doi:10.1002/anie.201204373

34. Venkatesan, A.; Ramesha, C. K.; Kannan, E. S. J. Phys. D 2016, 49 , 45301. doi:10.1088/0022-3727/49/24/245301 


\section{License and Terms}

This is an Open Access article under the terms of the Creative Commons Attribution License

(http://creativecommons.org/licenses/by/4.0), which permits unrestricted use, distribution, and reproduction in any medium, provided the original work is properly cited.

The license is subject to the Beilstein Journal of Nanotechnology terms and conditions:

(http://www.beilstein-journals.org/bjnano)

The definitive version of this article is the electronic one which can be found at:

doi:10.3762/bjnano.7.133 